\title{
Como as restrições sociais e estruturais compõem a identidade do falante
}

\author{
How social and structural constraints compose the speaker's identity \\ Dermeval da Hora \\ Universidade Federal da Paraíba - João Pessoa - Paraíba - Brasil \\ Pedro Felipe Lima Henrique \\ Universidade Federal da Paraíba - João Pessoa - Paraíba - Brasil
}

$\diamond$

\begin{abstract}
Resumo: A sociolinguística variacionista tem contribuído, desde os primeiros estudos realizados no Brasil, para que, a partir de estudos descritivos, possamos delinear os perfis dos falantes em suas diferentes comunidades. Os avanços nesse ramo da Linguística, com foco que correlaciona aspectos sociais, estruturais e estilísticos, dizem muito a respeito da persona individual e de como a comunidade se define em termos do seu falar. Nosso objetivo neste texto é apresentar, em linhas gerais, como as restrições sociais e estruturais, correlacionadas ao uso de algumas variáveis, podem contribuir para a construção da identidade do falante, observando o encaixamento dessas variantes na comunidade, assim como refletir a respeito de questões como percepção, estilo, atitude e sua relação e com essa identidade. Os estudos utilizados resultam de pesquisas realizadas com o corpus do Projeto Variação Linguística no Estado da Paraíba VALPB (HORA, 1993), todos eles voltados para aspectos fonético-fonológicos.
\end{abstract}

Palavras-chave: Variação linguística; Atitude; Estilo; Percepção

\begin{abstract}
The variationist sociolinguistics has contributed, since the first studies in Brazil, to delineate, from descriptive studies, the speakers' profiles in their different speech communities. Advances in this branch of linguistics, focusing in the correlation of social, structural and stylistic aspects show very much about the individual persona and about how the community defines itself in terms of the way it speaks. The goal of this text is to present, as an outline, how the social and structural constraints, correlated to the use of some variables, can contribute to the construction of the speaker identity, taking into consideration the embedding of these variants in the community, as well as reflect about perception, style, attitude and their relationship with this identity. These studies result of research developed with the corpus of Projeto de Variação Linguística da Paraíba - VALPB (HORA, 1993), all of them directed to phonetic-phonological aspects.
\end{abstract}

Keywords: Language variation; Attitude; Style; Perception

\section{Introdução}

Quando pensamos na disciplina Sociolinguística, temos consciência de que ela não se volta apenas para um objeto de estudo. Ela pode contemplar várias áreas de interesse, indo de estudos dialetais, interacionais, educacionais, culminando com estudos variacionistas. Em todas essas áreas não são poucos os estudiosos nas universidades brasileiras, desenvolvendo pesquisas que só têm contribuído para uma melhor compreensão da língua portuguesa como um todo e também de suas especificidades.
Na perspectiva variacionista, a que nos interessa mais de perto, os estudos sociolinguísticos no Brasil datam dos anos 1970 e, desde então, evoluíram, colocando o país como um dos principais centros mundiais, com uma quantidade significativa de pesquisas, indo além de meras descrições.

O Projeto Competências Básicas do Português, coordenado e implementado por Anthony Julius Naro e Miriam Lemle no Rio de Janeiro em 1977, é um dos marcos da gênese dos estudos variacionistas no Brasil. A partir dele, e com a formação de profissionais de diferentes regiões, pautando-se em sua base teórico- 
metodológica, deu-se o processo de difusão de uma área que foi se consolidando ano após ano. Com foco inicial no sudeste, espalhou-se para as demais regiões e hoje, em todo o Brasil, não é raro encontrar, nos programas de pós-graduação, docentes que desenvolvam projetos nessa vertente.

A língua portuguesa, a partir desses estudos, passou a ser descrita com mais acuidade, assumindo um perfil com características próprias de norte a sul, desnudandose em suas múltiplas variedades, principalmente quanto à fonologia e à sintaxe, aspectos mais explorados sob a base variacionista.

Os estudos realizados no Brasil sob tal perspectiva sempre consideraram a correlação entre as variáveis dependentes e suas restrições de caráter social e estrutural. Poucos são os estudos que buscam essa correlação com os aspectos estilísticos.

Do ponto de vista das restrições sociais, três conjuntos de fatores foram os mais trabalhados: o sexo, a faixa etária e a escolaridade. Já do ponto de vista das restrições estruturais, há uma variedade de possibilidades, dependendo do estudo que está sendo realizado. Se fonético-fonológico ou sintático, as restrições estruturais são bastante diversificadas, podendo variar dentro de estudos similares, principalmente se realizados por pesquisadores diferentes.

Nosso objetivo nesse texto é apresentar, em linhas gerais, como as restrições sociais e estruturais, correlacionadas ao uso de algumas variáveis, podem contribuir para a construção da identidade do falante, observando o encaixamento dessas variantes na comunidade, assim como refletir a respeito de questões como percepção, estilo, atitude, percepção e sua relação e com essa identidade. Os estudos utilizados resultam de pesquisas realizadas com o corpus do Projeto Variação Linguística no Estado da Paraíba - VALPB (HORA, 1993), todos eles voltados para aspectos fonéticofonológicos.

Assim, este texto, para cumprir tal objetivo, tem a seguinte estrutura: na seção 1, trataremos das restrições sociais e do encaixamento das variantes fonéticofonológicas descritas a partir dos dados do VALPB de acordo com as variáveis sociais; na seção 2, discutiremos a questão do estilo nos estudos sociolinguísticos; na 3, abordaremos como a atitude pode desempenhar um papel importante no processo de variação; e, por último, na seção 4 , discutiremos sobre como os estudos envolvendo percepção e atitude, centrados nos ouvintes em comunidades de prática, podem relevar aspectos da identidade linguística de um grupo de falantes. Para tal, utilizaremos como exemplo a variante palatalizada da consoante pós-vocálica medial no dialeto pessoense.

\section{Perfil do falante que compõe a estratificação do corpus utilizado}

Quando, em 1993, demos início ao Projeto Variação Linguística no Estado da Paraíba, nosso principal objetivo era traçar o perfil linguístico do falante paraibano, mais especificamente de João Pessoa - capital do estado, considerando aspectos fonético-fonológicos, sintáticos, semânticos e discursivos. Com isso em mente, compusemos uma estratificação social, considerando as seguintes características: sexo, faixa etária e anos de escolarização. Por que a escolha dessas restrições sociais?

\subsection{A restrição sexo}

Nos trabalhos já realizados à época no Brasil, tanto no Rio de Janeiro, com o Projeto PEUL (Programa de Estudos sobre o Uso da Língua), como na região sul, com o Projeto VARSUL (Variação Linguística na Região Sul), estas eram as restrições utilizadas. Por serem elas inerentes ao falante, entendemos que a sua correlação com as variáveis dependentes a serem trabalhadas caracterizariam a comunidade que seria nosso objeto de estudo.

A restrição sexo esteve presente em quase todos os estudos sociolinguísticos realizados no Brasil, mas nem sempre ela foi selecionada como significativa. Sua inclusão deveu-se sempre ao fato de ela dividir as amostragens entre sexo masculino e sexo feminino.

Há, entretanto, estudos que selecionam a restrição sexo pelo seu grau de importância. Comparando os estudos sobre a palatalização das oclusivas dentais de Bisol (1985) e Hora (1993), observamos que em ambos os estudos o sexo foi selecionado, mas não com o mesmo resultado. Se em Bisol (1985) os falantes do sexo feminino favorecem a palatalização das dentais, em Hora (1993) são os homens que a favorecem. O que isto pode significar? Uma avaliação desse resultado pode nos levar a crer que no sul as mulheres estão usando a forma mais inovadora, a palatalizada, enquanto na comunidade pessoense quem está inovando é o falante do sexo masculino. Não é difícil de avaliar que, na comunidade pessoense, o homem tem uma função de chefe de família muito mais acentuada do que no sul, o que o faz estar mais tempo fora de casa. Isto, consequentemente, o coloca em contato mais direto com falantes de outras comunidades, que, possivelmente, devem ter a forma palatalizada como uso.

Corroborando os dados encontrados por Hora (1993) no que diz respeito ao uso da variante não padrão, o trabalho de Marques (2001) sobre a produção variável do fonema $/ \mathrm{v} /$ no dialeto pessoense selecionou o sexo como variável social relevante, apontando o feminino como favorecedor da utilização da variante não 
padrão [h], como em "fala[h]]a", com peso relativo de 0.54. Em contrapartida, o autor demonstra uma oscilação no comportamento dos sexos na comunidade quando cruza as variáveis sexo e faixa etária. A partir do cruzamento, constatou-se a apenas as mulheres na faixa etária entre 15 e 25 anos apresentaram, com maior frequência, a forma inovadora na sua fala. Nas outras faixas, a variante não padrão foi a predominante no comportamento linguístico dos informantes do sexo masculino, o que corrobora a hipótese de que as mulheres preferem a forma de prestígio.

No que se refere ao apagamento da oclusiva dental /d/, como em "fazen[ø]o" ao invés de "fazen[d]o", Martins (2001) aponta que os homens realizam mais o apagamento que as mulheres, com peso relativo de 0.54 . Estas inibem o processo, com peso relativo de 0.46 , e privilegiam o uso da variante padrão. Pereira (2010), em seu estudo envolvendo as vogais médias pretônicas, constatou que as mulheres na faixa etária entre 25 e 49 anos favorecem as formas inovadoras fechadas /e/ e /o/, enquanto os homens as inibem. Em outras faixas etárias, a escolha pela variante inovadora é mais sutil pelas informantes do sexo feminino, mas sempre menos frequente entre os informantes do sexo masculino em todas as faixas etárias.

Segundo Labov (1972), não podemos falar de um potencial inovador, mas, sim, potenciais inovadores, envolvendo ambos os sexos, o que define um ou outro como inovador é o tipo de variável que está sendo estudada.

Ocorrências dessa natureza contribuem para compor a identidade social do falante, definindo, em nível do sexo, a preferência por uma variante ou outra.

Equivocadamente, alguns estudos têm substituído o sexo pelo gênero, sem mesmo conhecer o perfil do informante. Sabemos que o sexo é algo definido biologicamente, enquanto o gênero é algo que se constrói ao longo do tempo. Também sabemos que é uma atitude muito simplista classificar o gênero apenas como masculino e feminino, e aí reside o equívoco.

Entendemos que, do ponto de vista da identidade do falante, é muito mais coerente falarmos de gênero do que de sexo. Somos todos homens e mulheres com características sociais que se confundem por mais que a sociedade procure impor determinados valores. Hoje, já não podemos acreditar que mulheres vivem sempre como domésticas, as rainhas do lar já fazem parte do passado, e isso tem influência direta na forma de falar, é o resultado do contato com outros falantes de comunidades que usam variantes diversas. Mesmo em se tratando do gênero, que aparece dicotomizado em masculino e feminino, entendemos ser um equívoco, pois sabemos que esta é uma forma simplista de reduzir a persona do ser humano que tem uma multiplicidade de valores.

\subsection{A restrição faixa etária}

Ao tratarmos da faixa etária, pensamos em três grupos: (a) 15 a 25 anos; (b) 26 a 49 anos; e (c) mais de 49 anos. O que nos motivou essa estratificação foi a inserção do falante no mercado de trabalho.

Essa variável tem sido relevante nas pesquisas sociolinguísticas, devido à existência de diferentes comportamentos linguísticos ligados a faixas etárias distintas. Os estudos de Labov (1972) sobre o /r/ retroflexo pós-vocálico em Nova Iorque e a centralização dos ditongos /ay/e/aw/ em Martha's Vineyard corroboram essa observação na medida em que apresenta a tendência de os mais jovens privilegiarem as pronúncias mais inovadoras, enquanto que os mais velhos, a mais conservadora. Nessa perspectiva, a observação da variação a partir dessa variável social pode permitir observações acerca da estabilidade das variantes na comunidade linguística estudada ou do processo de mudança em progresso, a partir do que Labov (1972) denomina de "estudo em tempo aparente". A indução sobre a possibilidade da ocorrência desse tipo de mudança é feita a partir da observação do comportamento das variantes nos grupos etários: caso se observe uma maior produtividade de uma variante inovadora na faixa etária dos mais jovens e sua menor expressividade na faixa etária dos mais velhos, a distribuição retilíneo dessa função pode apontar para uma mudança em progresso.

Marques (2001), no estudo citado anteriormente sobre a variação do fonema $/ \mathrm{v} /$, constatou que o resultado da representação da função entre idade e a produtividade da variante inovadora é um gráfico curvilíneo, de modo que a faixa etária mais jovem (15-25 anos) e mais velha (+ de 49 anos) inibem a aplicação do enfraquecimento da fricativa, ou seja, da produção como aspirada, enquanto que a faixa etária intermediária (26-49 anos) tende a utilizar a variante aspirada. Essa configuração atesta um processo de variação estável.

$\mathrm{O}$ estudo envolvendo o apagamento da oclusiva dental /d/ em contexto de gerúndio (MARTINS, 2001) apresenta as faixas etárias inicial e intermediária agindo em conjunto como favoráveis ao processo, formando uma grande faixa etária (15-49 anos). Apenas os mais velhos parecem inibir a queda da oclusiva, mantendo a variante padrão conservadora.

Sobre o uso variável do ditongo em contexto de sibilante, como em "rap[ajs]" "rap[as]", Aquino (1998) constatou que as faixas etárias mais jovens inibem a ditongação, enquanto a mais velha favorece. Dessa forma, a autora caracteriza esse processo variável como mudança em progresso.

No que se refere ao comportamento das pretônicas, Pereira (2010) observou que a distribuição das altas e 
médias baixas não parece ser influenciada diretamente pela faixa etária, o que não ocorre com as fechadas, que parecem ser favorecidas pela faixa etária intermediária (26-49 anos), caracterizando uma variação estável.

Ademais, a variável faixa etária está ligada a um aspecto importante: a chamada idade institucional. Segundo Eckert (1998, apud BESERRA, 2004, p. 270), a idade pode influenciar as redes sociais dos informantes, "determinando suas necessidades por variedades linguísticas". Assim, o fato de os jovens estarem ligados ao ambiente escolar, repleto de normas e prescrições; de os adultos estarem num ambiente de trabalho, em que a exigência pela norma padrão é relativizada (a depender da função); e de os idosos, já fora do mercado de trabalho, tudo isso pode estar relacionado às escolhas feitas pelos falantes das faixas etárias específicas.

Apesar da possibilidade de se fazerem inferências acerca do processo de mudança a partir da observação da distribuição das variantes entre as faixas etárias, apenas um estudo em tempo real pode ratificar se o processo de mudança realmente vem sendo implementado na comunidade de fala e qual sua direção.

\subsection{A restrição anos de escolarização}

A variável "anos de escolarização" está estritamente relacionada ao status de prestígio e conservadorismo que determinadas variantes apresentam numa comunidade de fala, segundo os resultados dos estudos sociolinguísticos que consideraram essa restrição social em suas análises. Geralmente, as variantes padrão estão mais presentes na fala dos informantes mais escolarizados, enquanto que os menos escolarizados tendem a utilizar as formas não-padrão.

Grande parte das análises desenvolvidas com base nos dados de fala de João Pessoa apontaram, como variável relevante para o processo fonológico estudado, a escolaridade dos informantes. O trabalho de Silva (1997), referente ao processo de monotongação, como em "p[ej]xe" "pe[x]e" e t[ow]ro" "t[o]ro", apresenta a variável escolaridade como relevante para o fenômeno, sendo a variante monotongada a mais frequente na fala dos menos escolarizados. Algo parecido acontece nos dados apresentados por Aquino (1998) no que se refere à ditongação em contexto de sibilante. Os falantes mais escolarizados parecem inibir a regra de ditongação, enquanto que os menos escolarizados a favorecem.

Martins (2000), sobre o apagamento do /d/ no gerúndio, a exemplo de "falando, escrevendo", afirma que a variante padrão (sem o apagamento) é mais produtiva entre os informantes mais escolarizados, enquanto o apagamento é favorecido entre os informantes com menos escolaridade. Os resultados de Marques (2001) sobre o enfraquecimento do fonema $/ \mathrm{v} /$ também corroboram os resultados anteriores: a variante inovadora e com menos prestígio - a realização glotal - é mais frequente entre os menos escolarizados do que entre os mais escolarizados, sendo de 0.30 a diferença entre o peso relativo dos analfabetos e dos falantes universitários dentro do tratamento estatístico para a aplicação da regra em cada uma das variantes.

Sobre as vogais médias pretônicas, Pereira (2010, p. 80) constatou que "ao mesmo tempo em que favorecem mais as variantes fechadas ê/ô, os universitários são os que apresentam os índices mais baixos para a elevação das médias para i/u". Dessa forma, os falantes com menos anos de escolarização são os que apresentam maiores índices de elevação. A partir desse dado pode-se inferir que, em certo grau, a variante fechada, mesmo que pouco produtiva, pode ser considerada como uma variante de prestígio para a comunidade em relação às vogais altas, por exemplo, na posição pretônica.

Concluímos, a partir dos dados relatados acima, que a participação da escola estabelece-se como decisiva para o condicionamento do comportamento linguístico de uma comunidade de fala. Algumas variantes conservadoras como a não ditongação antes de sibilante e a não monotongação de falsos ditongos revelam, por exemplo, a aproximação da língua falada com a língua escrita, algo que a escola tradicional legitima e incentiva. Dessa forma, relações sociais com pessoas mais escolarizadas, por vezes, forçam o falante a adotar um comportamento linguístico mais formal, com a adoção de variantes mais conservadoras e que, na maioria das vezes, é avaliada como de prestígio. Essa é uma possível relação que podemos fazer, inclusive, entre essa variável e a noção de comunidades de prática, sobre a qual falaremos nas seções posteriores.

\section{0 estilo nos estudos sociolinguísticos}

Dentro da tradição dos estudos sociolinguísticos no Brasil sob a perspectiva variacionista, seguindo Weinreich, Labov, Herzog (1968) e Labov (1966, 1972), como já afirmamos no início deste artigo, dois conjuntos de restrições foram tomadas: as sociais e as linguísticas. Até então, as restrições estilísticas nunca foram consideradas. Dentre as concepções de estilos, duas parecem promissoras para o tratamento da variação: a concepção de Labov (1966) e a de Eckert (2000).

$\mathrm{Na}$ acepção laboviana, o estilo está ligado diretamente a uma atividade metalinguística acionada em contextos específicos (de formalidade, de tensão), em que o indivíduo é levado a prestar atenção no seu modo de falar, automonitorando-se. Os insights para a formulação do estilo nesses termos tiveram sua gênese nos trabalhos com 
a comunidade de Nova Iorque, em 1966, quando, com o intuito de formalizar um instrumento de coleta de dados que permitisse ao linguista comparar seus resultados, ele se deparou com um paradoxo: como obter a fala natural do informante a partir de um instrumento formal? Para resolver esse problema, o linguista direcionava as entrevistas a partir de níveis de formalidade. Percebeu que, em alguns tipos de narração, os falantes mostravam-se tão envolvidos emocionalmente que pareciam esquecer-se da presença do gravador. Quando eram induzidos a referir-se a seu modo de falar, o cuidado com a linguagem parecia ser mais acentuado. Dessa forma, Labov esboça a entrevista sociolinguística de forma que possa obter do falante, tanto quanto possível, uma fala que vá da mais casual à mais formal. Segundo Coupland (2007, p. 7), Labov entende que a variação linguística pode ser detectada quando as pessoas falam 'menos cuidadosamente' em alguns pontos da entrevista mais do que em outros pontos. Quando elas estão mais relaxadas, elas utilizarão traços do vernacular com maior frequência.

Ainda para os autores, enquanto a noção de prestígio desempenha um importante papel no trabalho de Labov sobre estilo, é a atenção prestada à fala que ele coloca como foco, presumivelmente porque a atenção é o mecanismo cognitivo que liga o social aos fatores linguísticos. Ao colocar o prestígio na parte mais alta da hierarquia socioeconômica e o estigma na parte mais baixa, Labov caracterizou cada continuum estilístico do falante em relação a esses dois polos. Ele viu o prestígio da variedade do falante como o resultado da fala formal, cuidada, e o estigma como o resultado da fala casual, não monitorada.

O estudo sobre a variação estilística em New York City (1966) é considerado um dos mais importantes construtos na área. Apesar de sua importância, o estilo deixou de ser o foco das pesquisas quantitativas na década seguinte, e isto, segundo Ricford e Eckert (2001, p. 3) se deve, parcialmente, (a) ao questionamento sobre a atenção prestada à fala como foco da pesquisa; (b) à dificuldade operacional de separar a fala casual da fala cuidada a partir das situações contextuas e (c) ao fato de os pesquisadores se voltarem mais para as restrições linguísticas e sociais ligadas à variação. Segundo Eckert e Rickford (2001, p. 3), o estudo de Labov (1966) estabelece uma forte ligação entre o indivíduo e a comunidade - entre o linguístico, o cognitivo e o social.

\section{O papel da atitude no processo de variação}

No primeiro trabalho sobre atitude, Allport (1935, p. 801) afirmou que atitude era um dos conceitos fundamentais na psicologia social e, na sociolinguística, tem sido um conceito central desde o trabalho seminal de Labov (1966) sobre a estratificação social das comunidades de fala e sobre como a mudança linguística é influenciada pelo prestígio e pelo estigma em relação a traços linguísticos específicos existentes nas comunidades. O conceito de atitude, contudo, nem sempre é facilmente delineado. Suas definições variam com o grau de elaboração e com o peso dado a diferentes traços de atitudes.

Um estudo sobre atitudes na comunidade de João Pessoa foi realizado por Hora (2011), que apresenta uma análise qualitativa das respostas dadas pelos informantes do corpus do VALPB no que diz respeito às atitudes dos falantes quanto à fala e ao papel da sua percepção/ consciência sobre os processos variáveis. Essa coleta foi feita a partir de uma "abordagem direta", em que os falantes são solicitados a emitir suas opiniões a respeito da sua própria fala e de outrem. Os sessenta informantes entrevistados, estratificados socialmente em idade, escolaridade e sexo, foram submetidos a perguntas do tipo:
1 - O que você acha do seu modo de falar?
2 - Você acha que fala diferente das pessoas que residem em João Pessoa?
3 - E em relação a como falam os outros brasileiros?
$4-\mathrm{O}$ que acha que torna o falar paraibano diferente dos outros falares do Brasil?
5 - Gostaria de falar diferente?
6 - O que significa falar bem? (HORA, 2011, p. 30).

Os resultados apontaram que as respostas não foram muito diferenciadas quando se levou em consideração a variável sexo. Os anos de escolarização, entretanto, fizeram a diferença. Em todas as faixas etárias, os informantes apontavam aspectos globais, como os prosódicos, entonacionais, que expressam juízo de valor a respeito da maneira como as pessoas falam (arrastado, ligeiro, cantando, etc.), o que caracteriza o sotaque (2011, p. 33). Em relação aos aspectos pontuais, a percepção fica mais aguçada à medida que a escolarização aumenta. Os falantes mais escolarizados chamaram a atenção para a realização do " $r$ " paulista, o chiado ou assoprado correspondente a palatalização da fricativa e das oclusivas dentais no falar carioca e a realização do "s" no falar gaúcho.

Apesar de haver diversas outras diferenças em relação ao modo de falar dos paraibanos e os outros presentes no Brasil no que diz respeito a aspectos fonético-fonológico, apenas os relatados no parágrafo anterior foram apontados pelos informantes. Essas variantes são consideradas por Labov (1972) como estereótipos, já que os indivíduos percebem sua presença na fala das pessoas e as utilizam para identificar um sotaque de uma região. Por outro lado, as variantes marcadores e indicadores, por não estarem 
no nível da consciência dos falantes de uma comunidade linguística, não são por eles apontados.

\section{Os estudos de percepção e a atenção para o ouvinte: o caso da palatalização da fricativa pós-vocálica}

Pesquisadores que trabalham com os campos da sociolinguística e da percepção da fala têm fornecido muitas evidências para sustentar a noção de que a variação linguística entre os falantes que se deve a diferenças regionais e étnicas é real e robusta e é uma importante propriedade da língua falada. Sabemos menos do que os 'leigos' ouvintes sabem sobre essas fontes de variação. Enquanto os sociolinguistas gastam muito de seu tempo documentando a variação linguística que existe, os pesquisadores de percepção da fala têm devotado seu tempo e esforço a reduzir ou eliminar essas fontes naturais da variabilidade ou simplesmente ignoram-nas inteiramente.

Há várias metodologias de pesquisa, contudo, que têm sido usadas para investigar a questão sobre o que os "leigos" ouvintes sabem sobre variação linguística étnica e regional. Algumas dessas metodologias experimentais se originam da psicologia social, tais como julgamentos de atitude e a técnica matched-guise. Outras têm sido desenvolvidas no campo da dialetologia perceptual, tais como as tarefas de map-drawing. Ainda outras se originam da linguística forense, como a imitação do sotaque e a caricatura. Finalmente, mais recentemente, vários pesquisadores têm explorado métodos experimentais desenvolvidos na psicologia cognitiva para explorar a percepção da variação nas tarefas de discriminação, identificação e categorização.

Para Klatt (1989), há importantes razões teóricas envolvidas na compreensão da variação dialetal e da percepção.A fim de melhor entendermos o processo de percepção da fala humana, necessitamos aprender mais sobre como as principais fontes de variação são percebidas e codificadas ao longo da mensagem linguística do enunciado.

Pesquisadores dos mais diversos campos psicologia social, sociolinguística, linguística forense, psicolinguística e psicologia cognitiva - têm contribuído para o número crescente de estudos sobre a relação entre variação regional, social, étnica e a percepção da fala. Os resultados desses diferentes estudos, como afirmam Clopper e Pisoni (2005, p. 333-334), revelam que os ouvintes leigos são conscientes da variação linguística à medida que eles podem imitá-la, usá-la para identificar de onde são as pessoas e fazer julgamentos sobre as características sociais dos falantes.

Dentro desse contexto, o Projeto Variação Linguística da Paraíba, em sua terceira fase, além de propor um estudo em tempo real de alguns dos processos fonológicos já descritos a partir do corpus coletado em 1993 por meio de um retorno à comunidade de fala 20 anos após a primeira coleta, também tem por intuito analisar como os ouvintes dessa comunidade percebem e avaliam algumas das formas que estavam em variação estável há 20 anos. Dentre as variáveis dependentes escolhidas para o projeto, falaremos sobre uma em específico para exemplificar como as análises envolvendo percepção e atitude podem ajudar a esclarecer questões sobre a forma como a uma variante se espalha numa comunidade, alargando ou, no mínimo, ressignificando o que se entendia por encaixamento.

A fricativa pós-vocálica /S/ pode ser realizada, no português brasileiro, na forma alveolar, fricativa, aspirada ou apagamento, como atestam vários estudos sociolinguísticos sobre dialetos do nordeste, sudeste e sul (CALLOU, LEITE, MORAIS, 2002; HORA, 2003; RIBEIRO, 2006; BRESCACINNI, 2002). Dessa forma temos produções do tipo "doi[s]" "doi[S]" "doi[ø]" e "le[s]te" "le[S]te" para a fricativa surda, e "me[z]mo" "me[h]mo" "me[3]mo" "me[ø]mo" e "de[z]de" "de[3]de" "de[h]de" para a sonora.

Com o intuito de descrever o comportamento dessa variável na comunidade de João Pessoa, Hora (2003) e Ribeiro (2006) lançaram mão dos dados do VALPB, o primeiro analisando a fricativa coronal em posição de coda interna, e a segunda, em posição de coda final em lexemas. Os resultados podem ser visualizados no gráfico abaixo:

Gráfico 1 - Disposição das variantes do /S/ pós-vocálico na cidade de João Pessoa

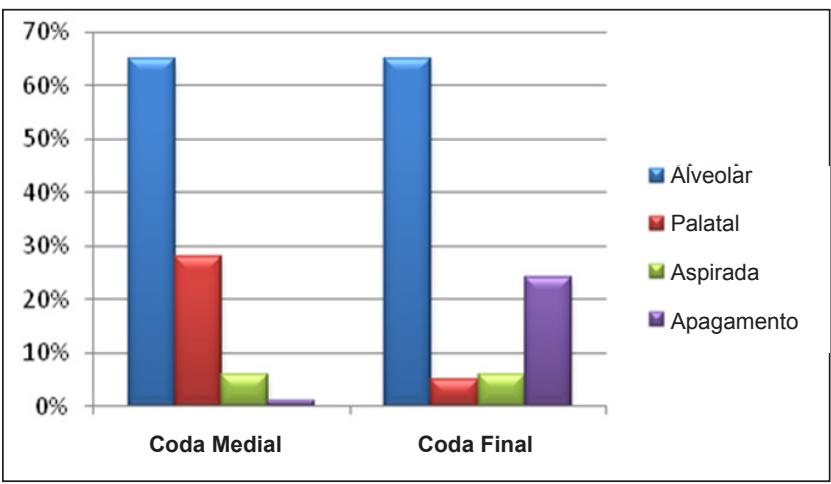

Fonte: Hora (2003) e Ribeiro (2006).

Os resultados de Hora (2003) apontam para a heterogeneidade do comportamento da fricativa coronal, prevalecendo a variante alveolar $(65 \%)$, seguida da palatal (28\%). Apesar de a forma alveolar ser preponderante, nota-se que ela não chega a ser categórica, pois a forma palatalizada está presente em $28 \%$ dos dados, o que, segundo o autor, tem motivação no contexto fonológico 
seguinte: a realização da palatal está diretamente condicionada à presença das consoantes oclusivas dentais $/ \mathrm{t}, \mathrm{d} /$, como em pa[S]ta, co[S]tura, de[3]dém e de[3]de. A variável "contexto fonológico seguinte" foi a única selecionada pelo programa como condicionante para a aplicação da regra, conferindo à variante "coronal" um peso relativo alto.

Em se tratando da posição final, o estudo de Ribeiro (2006) mostra que a fricativa coronal/S/, em sua realização palatalizada, é muito pouco produtiva, uma vez que ela aparece apenas em 5\% dos dados, prevalecendo, portanto a forma alveolarizada. Esses resultados demonstram mais uma evidência para o fato de que a palatalização é estritamente condicionada, no dialeto pessoense, às oclusivas dentais $[\mathrm{t}, \mathrm{d}]$ como contexto fonológico seguinte.

A partir dessas constatações temos uma restrição puramente linguística para a aplicação da regra de palatalização: o contexto das oclusivas dentais. É curioso, entretanto, que os falantes dessa comunidade tenham uma atitude negativa quanto à variante palatalizada, como ficou claro nos testes de atitude com abordagem direta: ao fazer referência à variante palatalizada, os falantes identificaram-na como "chiado" e "falar assoprado" associado ao falar carioca, o que evidencia a percepção da variante pela comunidade e sua configuração como estereótipo, segundo a classificação laboviana. Ficou evidente, pois, que o falante pessoense não percebe que ele próprio também a utiliza em determinados contextos, como aqueles em que o item tem no contexto fonológico seguinte uma das oclusivas dentais $/ \mathrm{t}, \mathrm{d} /$.

Partindo dessa premissa, decidimos elaborar testes de percepção e atitude a serem aplicados na comunidade de fala de João Pessoa com o objetivo de: (i) identificar se os ouvintes percebem a forma palatalizada em contextos de aplicação da regra em sua comunidade (coronais) e em outros contextos (labiais e dorsais); (ii) analisar o nível de consciência da variante que utiliza em cada contexto; (iii) avaliar as atitudes positivas e/ou negativas do falante em relação à variante palatalizada de acordo com a estratificação social por sexo, faixa etária e anos de escolarização; (iv) avaliar as atitudes positivas e/ou negativas dos falantes de uma comunidade de prática de alunos do curso de Letras sobre a variante palatalizada, estratificados de acordo com o sexo e a instrução formal ou não, para o experimento, em fonética e fonologia.

Para o desenvolvimento dessa pesquisa utilizamos duas metodologias: uma para a confecção e manipulação dos estímulos e uma para a aplicação dos testes de percepção. Quanto à confecção dos estímulos, dois informantes do sexo feminino e dois do sexo masculino, todos entre 20 e 24 anos, nascidos e residentes em João Pessoa e graduados em Letras - Português, gravaram um roteiro pré-estabelecido pelos pesquisadores contendo palavras isoladas e frases. As palavras isoladas foram gravadas dentro da frase veículo "Digo

baixinho", sendo o espaço ocupado pela palavra. Tanto as palavras como as frases apresentavam o /S/ pósvocálico na posição medial. Num primeiro momento, os informantes deveriam ler livremente as frases. Logo após, passavam por um treinamento para produzirem todas as fricativas de forma alveolar e, posteriormente, de forma palatal $^{1}$.

Obtidas as gravações, elas foram homogeneizados em relação ao volume no programa SoundForge 10.0 e tratadas no programa PRAAT. Foram, posteriormente, organizadas em dois grupos de estímulos. O primeiro grupo foi organizado em pares formados pela mesma palavra, pronunciada com a variante palatal e com a alveolar. Para nos certificarmos de que a única diferença entre as palavras era o segmento pós-vocálico, utilizamos a opção copiar e colar do PRAAT, de modo a mantermos a mesma produção e alterar apenas o segmento de uma delas para a outra variante. O segundo grupo de estímulos, composto pelas frases, foi normalizado da mesma forma e tratado conforme o recorte das palavras isoladas.

Esses dois grupos de estímulos configuraram dois grupos de teste. O primeiro grupo foi elaborado a partir do Software de aplicação TP. O falante ouvia pares de palavras, como "ago[s]to" e "ago[S]to" e tinha de responder a três perguntas: (i) A pronúncia das palavras foi igual ou diferente? (ii) Os pessoenses falam como a primeira ou a segunda pronúncia? (iii) Você fala como a primeira ou a segunda pronúncia? ${ }^{2}$ A primeira questão objetiva identificar se a variante é saliente à percepção dos ouvintes da comunidade; a segunda, que variante eles identificam como a prototípica em sua comunidade de fala; e a terceira, que variante eles acreditam produzir. Esses dados serão confrontados com os dados de produção dos informantes, na forma de inquérito fonético, em que o informante informará que figura está sendo a ele apresentada. Essas imagens foram selecionadas de acordo com os contextos fonológicos e a variável dependente analisada na pesquisa.

\footnotetext{
1 O treinamento foi realizado de modo a se obter consoantes com parâmetros acústicos distintos para as fricativas estridentes, dentre os quais a ressonância em regiões de frequência alta, para as fricativas alveolares, e em regiões de frequência mais baixas, para as palatais, ambas como reflexo da diferença entre os locais em que acontecia a constrição no trato vocal, se mais anterior (alveolar) ou mais posterior (palatal). Alguns estudos estão sendo realizados no VALPB sobre o parâmetro para a percepção de fricativas estridentes e Henrique e Belo (2015) observaram que, na comunidade de fala de João Pessoa, as alveolares são reconhecidas como tais quando o pico espectral da fricativa está acima de $6,5 \mathrm{kHz}$, enquanto que as palatais são prototipicamente reconhecidas como tais quando possuem um pico spectral abaixo de $4 \mathrm{kHz}$.

2 O primeiro teste é o que a literatura chama de "teste categorização". O segundo e o terceiro configuram-se como testes de "identificação".
} 
O segundo grupo de estímulos foi aleatorizado de forma a não se repetir dentro do teste, de modo a obtermos números pareados de estímulos em contexto favorecedor ou não da regra fonológica na comunidade. Cada frase era ouvida pelo falante e, logo após, algumas perguntas sobre a dona da voz eram feitas ao ouvinte, como preconiza a técnica denominada matched guise. Nela, os ouvintes avaliam atributos dos falantes a partir de uma Escala de Avaliação de Atitudes Relacionadas à Fala, marcando suas respostas em uma escala de diferencial semântico de sete pontos, com os adjetivos positivos colocados à esquerda e os negativos, à direita.

A partir desse julgamento de atitudes relacionadas à ocorrência ou não da variante em análise, poderemos verificar se ela é considerada positiva para o falar de João Pessoa e para a fala do próprio ouvinte, o que pode relacionar-se ao processo de estigmatização ou prestígio da forma palatalizada.

\section{Considerações finais}

O que as pesquisas nos diferentes programas de pósgraduação que trabalham a perspectiva da sociolinguística variacionistra têm confirmado, a partir de suas linhas de pesquisa, a que se vinculam projetos e disciplinas, é a sua força no Brasil desde as duas últimas décadas do século XX. Foi um tímido começo, mas que atraiu a atenção de estudiosos de norte a sul.

É impossível ficarmos calados quando o assunto é a variação linguística. Especialistas na área ou não sempre têm algo a dizer, pois a variação é inerente ao ser humano. Poderíamos dizer para os primeiros, principalmente, que os estudos descritivos realizados nessa perspectiva mostram-nos como uma determinada variável dependente, seja ela fonético-fonológica, seja ela sintática, se correlaciona a fatores sociais e estruturais. Essa correlação está presente na maioria dos estudos, e, aos poucos, vão surgindo trabalhos que buscam essa correlação nos fatores estilísticos.

Associados aos primeiros estudos realizados, muitos deles mencionados neste artigo, novas propostas surgem, contribuindo para a definição do falante e de sua identidade social, delineando sua persona. E para contribuir com essas análises, os estudos voltados para ouvinte assumem um lugar fundamental. É nessa perspectiva que trabalhar com atitude, com percepção e com estilo torna-se fundamental para o futuro da sociolinguística em sua perspectiva variacionista.

\section{Referências}

ALLPORT, Gordon. Attitudes. In: MURCHISON, Carl (Ed.). A handbook of social psychology. Worcester: Clark University Press, 1935.
AQUINO, Maria de Fátima de Souza. A ditongação na comunidade de João Pessoa: uma análise variacionista. 1998. 84 f. Dissertação (Mestrado em Letras) - Curso de PósGraduação em Letras, Universidade Federal da Paraíba, João Pessoa, 1998.

BESERRA, Ana Clarissa Santos. A importância das variáveis sociais na formação do perfil linguístico do falante pessoense. In: HORA, Demerval da (Org.). Estudos sociolingüísticos: perfil de uma comunidade. João Pessoa: UFPB, 2004. p. 259-286.

BISOL, Leda. A palatalização e sua restrição variável. Relatório de pesquisa mimeo. Universidade Federal do Rio Grande do Sul, 1985. Mimeo.

BRESCANCINI, Cláudia Regina. A palatalização da fricativa alveolar não-morfêmica em posição de coda no português falado em três regiões de influência açoriana do município de Florianópolis - uma abordagem não-linear. 1996. $246 \mathrm{f}$. Dissertação (Mestrado) - Programa de Pós-Graduação em Línguística, Universidade Federal de Santa Catarina, 1996.

CALLOU, Dinah; MORAES, João; LEITE, Yonne. Processo(s) de Enfraquecimento Consonantal no Falar Português do Brasil. In: ABAURRE, Maria Bernadete Marques; Rodrigues Ângela Cecília (Org.). Gramática do Português Falado. Campinas: UNICAMP, 2002 .

CLOPPER, Cynthia; PISONI, David. Perception of dialect variation. In: PISONI, David; REMEZ, Robert. The handbook of speech perception. Oxford: Blackwell Publishing, 2005.

COUPLAND, Nikolas. Style: language variation and identity. Cambridge: Cambridge University Press, 2007.

ECKERT, Penelope. The whole woman: sex and gender differences in variation. In: MILROY, James. Language variation and change 1. Cambridge: Cambridge University Press, 1989. p. 245-268.

ECKERT, Penelope. Linguistic variation as social practice. Oxford: Blackwell, 2000.

ECKERT, Penelope; RICKFORD, John. Style and sociolinguistic variation. Cambridge: Cambridge University Press, 2001.

HENRIQUE, P. F. L.; BELO, G. Percepção das fricativas estridentes: a pista acústica para a distinção entre alveolares e palatais utilizadas pelos ouvintes pessoenses. 2015. Mimeo.

HORA, Dermeval da. Projeto Variação Linguística no Estado da Paraíba. João Pessoa: Universidade Federal da Paraíba, 1993. Disponível em: <www.projetovalpb.com.br>.

HORA, Dermeval da. Variação dialetal e atitude. In: HORA, Dermeval da; NEGRÃO, Esmeralda Vailati (Org.). Estudos da Linguagem: casamento entre temas e perspectivas. João Pessoa: Ideia/Editora Universitária, 2001, p. 15-36

HORA, Dermeval da. Fricativas coronais: analise variacionista. In: RONCARATI, Cláudia; ABRAÇADO, Jussara (Org.) Português brasileiro: contato lingüístico, heterogeneidade e história. Rio de Janeiro: Letras, 2003, p. 69-89.

KLATT, Dennis. Review of sected models of speech perception. In: MARSLEN-WILSON, William (Ed.). Lexical representation and process. Cambridge: MA - MIT, 1989, p. 169-226.

LABOV, William. The social stratification of English in New York City. Washington, D.C.: Center for Applied Linguistics, 1966. 
LABOV, William. Principles of linguistic change: social factors. Oxford: Blackwell, 2001.

MARQUES, Sandra Maria de Oliveira. A produção variável do fonema /v/ em João Pessoa. 2001. 93 f. Dissertação (Mestrado em Letras) - Programa de Pós-Graduação em Letras, Universidade Federal da Paraíba, João Pessoa, 2001.

MARTINS, Iara Ferreira de Melo. Apagamento da oclusiva dental /d/ no grupo -ndo na fala de João Pessoa. 2001. $110 \mathrm{f}$. Dissertação (Mestrado em Letras) - Programa de Pós-Graduação em Letras, Universidade Federal da Paraíba, João Pessoa, 2001.

PEREIRA, Regina Celi Mendes. Uma análise variacionista das vogais médias pretônicas. João Pessoa: Editora Universitária da UFPB, 2010.

RIBEIRO, Silvia Renata. Apagamento da sibilante final em lexemas: uma análise variacionista do falar pessoense. 2006.
110 f. Dissertação (Mestrado em Letras) - Universidade Federal da Paraíba, João Pessoa, 2006.

SILVA, Fabiana Souza. O processo de monotongação em João Pessoa. 1997. 104 f. Dissertação (Mestrado em Letras) Programa de Pós-Graduação em Letras, Universidade Federal da Paraíba, João Pessoa, 1997.

WEINREICH, Uriel; LABOV, William; HERZOG, Marvin. Empirical foundations for a theory of language change. In: LEHMANN, Winfred; MALKIEL, Yakov (Ed.). Directions for historical linguistics. Austin: University of Texas Press, 1968.

Recebido: 01 de setembro de 2015

Aprovado: 05 de outubro de 2015

Contato: dermeval.dahora@gmail.com pedrofelipelh@hotmail.com 